\title{
Ultrasonic NDE of Structural Ceramics for Power and Propulsion Systems
}

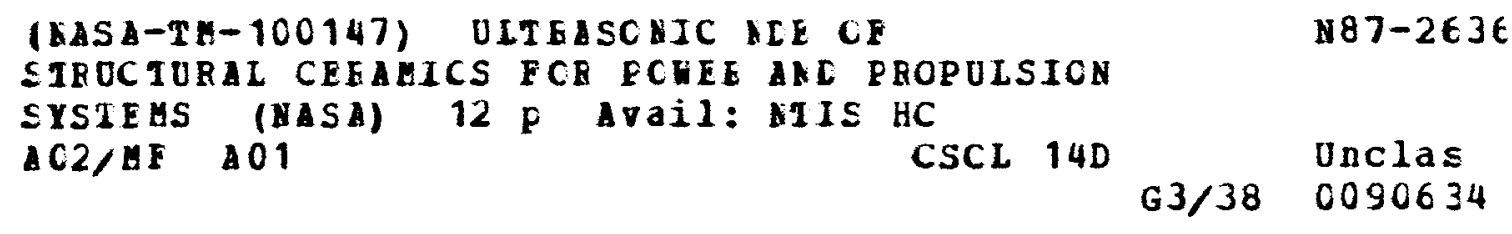

Alex Vary, Edward R. Generazio, Don J. Roth

Lewis Research Center

Cleveland, Ohio

and

George Y. Baaklini

Cleveland State University

Cleveland, Ohio

Prepared for the 4th European Conference on Non-Destructive Testing sponsored by the British Institute of Non-Destructive Testing London, England, September 13-18, 1987

\section{NMSA}




\title{
ULTRASONIC NDE OF STRUCTURAL CERAMICS FOR POWER AND PROPULSION SYSTEMS
}

\author{
Alex Vary, Edward R. Generazio, Don J. Roth \\ National Aeronautics and Space Administration \\ Lewis Research Center \\ Cleveland, Ohio 44135 \\ and \\ George $Y$. Baak.l ini \\ Cleveland State University \\ Cleveland, Ohio 44112
}

\begin{abstract}
SUMMARY
A review is presented on research investigations of several ultrasonic evaluation techniques applicable to structural ceramics for advanced heat engines. This review highlights recent work conducted under the sponsorship of and at the Lewis Research Center. Results obtained with scanning acoustic microscopy, scanning laser acoustic microscopy, photoacoustic microscopy, and scanning electron acoustic microscopy are compared. In addition to these flaw imaging techniques, microstructure characterization by analytical ultrasonics is described. The techniques were evaluated by application to research samples of monolithic silicon nitride and silicon carbide in the form of discs and bars containing naturally-occurring and deliberately-introduced flaws and microstructural anomalies. Strengths and limitations of the techniques are discussed.
\end{abstract}

\section{INTRODUCTION}

Monolithic silicon carbide and silicon nitride are current leading structural materials for many components in advanced power and propulsion systems. But, although both have good high temperature strength and oxidation resistance, they currently exhibit low toughness (brittleness) and unacceptable variability in their mechanical properties (Sheppard, 1986). The brittleness of ceramics can lead to sudden catastrophic failure under working stresses. These factors lead to unpredictable performance which is the most serious handicap to the use of monolithic ceramics in load-bearing structures. Moreover, these problems are aggravated by and usually traceable to poor control over flaw populations and nonuniformity of microstructure. Monolithic ceramics are very sensitive to minute flaws so that even flaws in the 20 to $50 \mu \mathrm{m}$ size range are likely to be critical. Examples of flaws that plague current monolithic ceramics appear in figure 1.

One approach to reliability is to screen out those ceramic parts that contain harmful flaws. Another approach is to use nondestructive evaluation. (NDE) techniques for process control. This includes use of NDE techniques during processing development research to detect flaws and to help devise ways to reduce the incidence of harmful flaws and also to ensure that ceramics exhibit correct microstructures and uniform properties. Thereafter, NDE is needed during various stages of production to ensure that only parts completely free of detrimental flaws and microstructural anomalies are installed in engines. 
This report describes the capabilities and limitations of several acoustic microscopy techniques for detecting minute flaws that can reduce the reliability of monolithic structural ceramics. In addition, analytical ultrasonic NDE for material characterization is discussed in connection with potentials for characterizing microstructure and thereby indirectly verifying the consistency and uniformity of mechanical properties.

\section{SCANNING LASER ACOUSTIC MICROSCOPY (SLAM)}

Representative SLAM images of flaws in ceramic samples appear in figure 2. The reliability of SLAM for flaw detection in silicon carbide and silicon nitride was evaluated by introducing known populations of microvoids into representative samples (Baaklini and Roth, 1986). Green ceramic powder compacts were seeded with plastic microspheres from 50 to $530 \mu \mathrm{m}$ diameter. Voids formed after volatilizing the spheres in a preheat treatment. The seeded voids remained after sintering the compacts into modulus-of-rupture (MOR) bars. The seeded microvoids were similar to natural voids that account for roughly 25 percent of fracture origins found in ceramic MOR specimens (Sanders and Baaklini, 1986). Sufficient numbers of seeded voids of various sizes were introduced to satisfy the generation of probability-of-detection (POD) statistics. POD results for SLAM are shown in figure 3.

It is evident from figures 2 and 3 that surface preparation by polishing or grinding is needed to enhance the detectability even of near-surface voids to the order of $50 \mu \mathrm{m}$ diameter. Surface roughness affects the single-to-noise ratio in SLAM images. Moreover, MOR bar samples with as-fired (as-sintered) surfaces show decreased flaw detectability with increased thickness. Flaw detectability also depends on the relative coarseness of the material microstructure. In silicon carbide samples flaw detectability was found to be significantly less than in silicon nitride samples that had a much finer grain structure (Roth and colleagues, 1986).

SLAM is an excellent research tool but has somewhat limited applicability to complex shapes usually found in heat engines. Access to opposing sides of a test object is needed. Applied to simple geometric shapes, SLAM does permit continuous real-time imaging (at video frame rates). SLAM can form a basis for assessing ultrasonic imaging methods and for visualizing wave propagation modes and in reactions (Generazio and Roth, 1986).

\section{SANNING ACOUSTIC MICROSCOPY (SAM)}

The SAM method described here is also called reflection acoustic microscopy (Nikoonahad, 1984). A SAM image appears in figure 4. Unlike SLAM images, SAM images are not instantaneous ( $i . e$. , not produced at video frame rates). SAM images are produced by mechanical microscanners so that it may take up to $10 \mathrm{~min}$ to image a $5 \mathrm{~mm}^{2}$ area with a $10 \mu \mathrm{m}$ line resolution. video frame rates are possible with high-speed, acousto-mechanical drivers. Then, the scanned area must be several orders smaller. These latter SAM devices achieve higher magnifications and usually operate at transducer frequencies approaching $1 \mathrm{GHz}$. This calls for metallurgically polished surfaces that are impractical for the inspection needs contemplated here. 
With SAM, access to only one side of a test object is needed. SAM can be adapted to curved surfaces by means of articulated probes. SAM can be used for surface and substrate characterization. By digitizing and saving the signals for each $x-y$ coordinate point considerable flaw characterization data can be stored for future retrieval and analysis. There is no limit on part thickness but depth of penetration is limited by attenuation of the high ultrasonic frequencies needed to resolve microflaws. Although much slower than SLAM, SAM produces sharper images of flaws and allows easier estimation of flaw depth. Precision in flaw definition and flaw location are gained by sacrificing speed since repeated frame scans are needed with the focal spot positioned at a different depth for each successive scan.

\section{PHOTO-ACOUSTIC MIRCOSCOPY (PAM)}

PAM is a thermo-acoustic method that depends on laser excitation of acoustic waves (Thomas and colleagues, 1980). The magnitude and phase of the acoustic waves are related to thermal property variations and proximity of material anomalies to the surface. The depth to which flaws can be detected depends on the material's thermal diffusion length.

PAM is readily adapted to complex shapes by designing appropriate isolation cells to contain them. Of the techniques mentioned so far, only PAM is essentially noncontacting (SLAM and SAM required liquid coupling). Conceptually, because it does not need liquid couplants that would be detrimental, PAM should be applicable to green samples. But PAM has a serious drawback. It has been found that laser beams with intensities sufficient to generate strong acoustic waves can mar the surface along the scan lines. Subsequent sintering of the marred samples apparently causes cracks in the scanned areas that do not appear in the unscanned areas ( $K 1 \mathrm{ima}$ and colleagues, 1986). Continued scanning of green samples tends to drive off substances that coat the cell window and occlude the laser beam. Hence, PAM seems inappropriate for green ceramics.

The spatial resolution of PAM images can be made comparable to that of either SLAM or SAM, but the resolution is obtained by sacrificing scan speed. For the same spatial resolution, PAM is the slowest of the three techniques. The ability to detect small flaws depends on scan line density and scan speed. The laser scan speed is limited by thermal inertia. The beam must dwell long enough at each point to produce a fixed number of thermal oscillations. It may take roughly 4 hours to $\operatorname{scan}$ a $1 \mathrm{~cm}^{2}$ area with a line resolution of $25 \mu \mathrm{m}$.

\section{SCANNING ELECTRON ACOUSTIC MICROSCOPY (SEAM)}

SEAM requires that the object to be examined be placed in a high vacuum scanning electron mircoscope (SEM) enclosure. Of the acoustic microscopy methods mentioned thus far, it is the least accommodating to heat engine components (Klima, Baaklini, and Able, 1986).

The SEAM technique is certainly appropriate for material research and for inspecting microelectronic circuit components and similar articles. Ceramics and other nonconductors need to be coated with a conducting layer to attract the beam electrons. A carbon deposit on silicon carbide or silicon nitride samples also enhances image contrast. The need for a high vacuum environment 
can pose a problem of some types of ceramic parts, especially if they tend to outgas. SEAM images can be produced at rates intermediate between SLAM and PAM. The image of a $5 \mathrm{~mm}^{2}$ area can be generated in roughly $1 \mathrm{~min}$. The line resolution of SEAM is of the order of $5 \mu \mathrm{m}$. The spatial resolution of SEAM images depend on the thermal wavelength while the depth of detection depends on the thermal diffusion length in the material (Rosencwaig, 1980). Preliminary investigations on silicon carbide and silicon nitride samples indicate that SEAM readily images superficial pits, nodules, and natural cracks.

\section{ANALYTICAL ULTRASONICS}

The primary objective of analytical ultrasonics is not to detect or characterize individual flaws but to characterize material microstructure and diffuse microflaw populations (e.g., mean grain size, grain size distribution, porosity, microcrack density). By characterizing the factors that govern extrinsic properties analytical ultrasonics can provide the basis for indirectly verifying mechanical properties and assessing service degradation of ceramic components (Vary, 1986, 1987).

One approach to analytical ultrasonics is based on contact, pulse-echo methodology where broadband, high frequency pulses are introduced into a sample (Generazio and colleagues, 1987). Reflections from the back surface of the sample are analyzed to obtain precise velocity and attenuation data over a wide frequency range. The data may be obtained by tak-ing a series of sampling measurements or by systematic scanning. In the latter case, the data are assembled into mappings of velocity and attenu- ation variations, figures 5 and 6 . These mappings can be correlated with variations in moduli, with microstructure, and ultimately with mechanical properties (strength, toughness).

The pulse-echo approach requires access to only one side of a test piece, but meaningful signal acquisition depends on part shape and certain accommodations between the probe and part. Ideally, the pulse-echo signal should be obtained between smooth, flat, and very parallel surfaces. Samples like discs or modulus-of-rupture (MOR) bars, with flat, polished surfaces are ideal and preferred. For parts with complex shapes it is necessary either to adapt probes or, occassionally, to design parts to accommodate the probes.

Pulse-echo measurements were made on a series of sintered silicon carbide MOR bars that were fabricated with deliberately varied microstructures (grain size), densities (porosity), and surface conditions (roughness). Figure 7 summarizes correlations among velocity, attenuation, and microstructural factors such as grain size and porosity. It is seen that large changes in the attenuation spectrum accompany changes in microstructure while corresponding changes in velocity are comparatively small. These findings indicate that ultrasonic attenuation measurements are pivotal in sensing microstructural variations and associated factors that govern strength, toughness and other extrinsic mechanical properties.

\section{DISCUSSION}

The four acoustic microscopy techniques compared in this paper have the ability to detect minute flaws in monolithic ceramics. The problem is to define the relative strengths and limitations of the techniques. Ideally, 
each technique should be evaluated in terms of probability of detection ( $P O D$ ) statistics. Otherwise, it is impossible to assert the essential merit of any given technique over another. Accomplishing this proves to be quite difficult because known populations of different kinds of likely flaws need to be systematically embedded in representative test samples. One frequently-occurring failure-causing flaw type can be represented by artificially implanted microvoids. This report covers POD statistics for only one technique, namely SLAM, to illustrate its microvoid detection capability. The SLAM example provides a touchstone for assessing the relative merits of the remaining acoustic microscopy techniques discussed herein.

Acoustic microscopy techniques should be considered for resolving flaws in the range from tens of microns to several hundred microns. To achieve sufficient spatial resolution it is necessary to restrict the area to be imaged, typically from $1 \mathrm{~mm}^{2}$ to about $1 \mathrm{~cm}^{2}$. Although there may be compelling reasons to inspect certain critical areas to the $10 \mu \mathrm{m}$ level of resolution, it is currently impractical to demand that every square millimeter of a ceramic heat engine part be scanned to resolve every $10 \mu \mathrm{m}$ flaw.

Although SAM appears to be the best technique for sintered ceramics no single acoustic microscopy technique can be cited as the preferred one and none of the techniques should be completely eliminated from consideration. If a technique is not suitable for hardware inspection, then it may be suitable as a resaarch tool. Each technique has at least one desirable feature lacking in the others. For example, SAM gives better flaw detection and definition than SLAM, but SLAM gives immediate images while SAM takes more time to image the same area.

Each acoustic microscopy technique was viewed relative to its applicability to green state and fully densified (e.g., sinered) ceramic components. Convenience in examining parts having complex shapes was also considered. Techniques that do not require contact probes are preferred for ease of inspection and. particularly, to avoid perturbing green state compacts. Ultrasonic methods usually require probes that make contact through a coupling medium. Noncontact methods that use lasers for producing and sensing ultrasonic waves are attractive alternatives. Of the methods described herein. PAM uses a laser beam to produce ultrasonic waves while SLAM uses a laser beam to detect ultrasonic signais that have propagated through a part.

At this writing, there exists no single laser ultrasonics technique that provides totally practical "laser-in, laser-out" acoustic microscopy or analytical ultrasonics. One technique that offers noncontact laser imaging capability is the so-called mirage technique (Inglehart, Thomas, and Schuldies, 1980). Other noncontact approaches belonging to this thermal wave imaging genre utilize infrared emission or probe beam reflection to detect flaws and anomalies. These latter techniques are under study and have reported resolutions of the order of $1 \mu \mathrm{m}$. Of course, this resolution capability is won at the expense of long times needed to produce an image. Moreover, they are subject to effects of surface roughness, curvature absorded layers, and binders/ volatilies in green state materials.

Analytical ultrasonics promises to be a key approach of the nondestructive assessement and verification of mechanical strength and toughness and property degradation in monolithic, particulate or whisker-toughened, and fiber reinforced ceramic matrix composities. Combined with acoustic microscopy for flaw 
detection and imaging, analytical ultrasonics should provide information needed to identify loci where isolated or clustered flaws are more likely to interact either with each other or with material microstructures in which they reside. Analytical ultrasonics complemented by mircofoucs radiography or computed tomography may be the only practical approach to assessing toughened ceramics and ceramic matrix composites in which individual flaws are too minute, numerous, and diffuse to justify attempts to image them separately using acoustic microscopy.

\section{CONCLUSION}

Two classes of ultrasonics techniques are reviewed in this paper: (1) acoustic microscopy techniques for flow detection and imaging; and (2) analytical ultrasonics of characterizing material microstructure and morphology. The former class involves detection and mapping of individual flaws an clusters of discrete flaws. The latter class involves indirect assessment of mechanical property variations that are governed by diffuse flaws populations, microstructure and morphology. The review given herein indicates merits and disadvantages of key ultrasonic approaches to ceramic NDE.

\section{REFERENCES}

1. Baaklini, G.Y., and D.J. Roth (1986). Probability of Detection of Internal Voids in Structural Ceramics Using Microfocus Radiography. J. Mater. Res., 1, 457-467.

2. Generazio, E.R., and D.R. Roth (1986). Quantitative Flaw Characterization With Scanning Laser Acoustic Microscopy. Mater. Eval., 44, 863-870.

3. Generazio, E.R., D.J. Roth, and G.Y. Baaklini, (1987). Imaging Subtle Microstructural Variations in Ceramics With Precision Ultrasonic Velocity and Attenuation Measurements. NASA TM-100129, Washington, D.C.

4. Inglehart, L.J., R.L. Thomas, and J. Schuldies (1980). Photoacoustic Microscopy of Ceramic Engine Hardware. J. Nondestr. Eval., 1, pp. 287-293.

5. Klima, S.J., G.Y. Baaklini, and P. B. Able (1986). Nondestructive Evaluation of Structural Ceramics. NASA TM-88978, Washington, D. C.

6. Nikoonahad, M. (1984). In R. S. Sharpe (Ed.) Research Techniques in Nondestructive Testing, Vol. 7, Academic Press, London, pp. 217-257.

7. Rosencwaig. A. (1980). Photoacoustics and Photoacoustic Spectroscopy. John Wiley and Sons, New York, 1980.

8: Roth, D.J., S.J. KIima, J.D. Kiser, and G.Y. Baaklini (1986). Reliability of Void Detection in Structural Ceramics Using Scanning Laser Acoustic Microscopy. Mater. Eval., 4,762-769, 761.

9. Sanders, W.A., and G.Y. Baaklini (1986). Correlation of Processing and Sintering Variables With the Strength and Radiography of Silicon Nitride. Ceram. Eng. Sci. Proc., 7, 839-859. (NASA TM-87251). 
10. Sheppard, L.M. (1986). Reliable Ceramics for Heat Engines. Adv. Mater. Processes, 2, 54-66.

11. Thomas, R.L., J.J. Pouch, Y.H. Wong, L.D. Favro, P.K. Kuo, and A. Rosencwaig (1980). Subsurface Flaw Detection in Metals by Photoacoustic Microscopy," J. Appl. Phys., 51, 1152-1156.

12. Vary, A. (1986). In J.D. Achenbach and Y, Rajapakse (Eds.), Solid Mechanics Research for Quantitative Non-Destructive Evaluation, Martinus Nijhoff Publishers, Dordrecht, The Netherlands, pp. 135-152.

13. Vary, A., ed. (1987). Materials Analysis by Ultrasonics: Metals, Ceramics, Composites. Noyes Data Corp., Park Ridge, NJ.

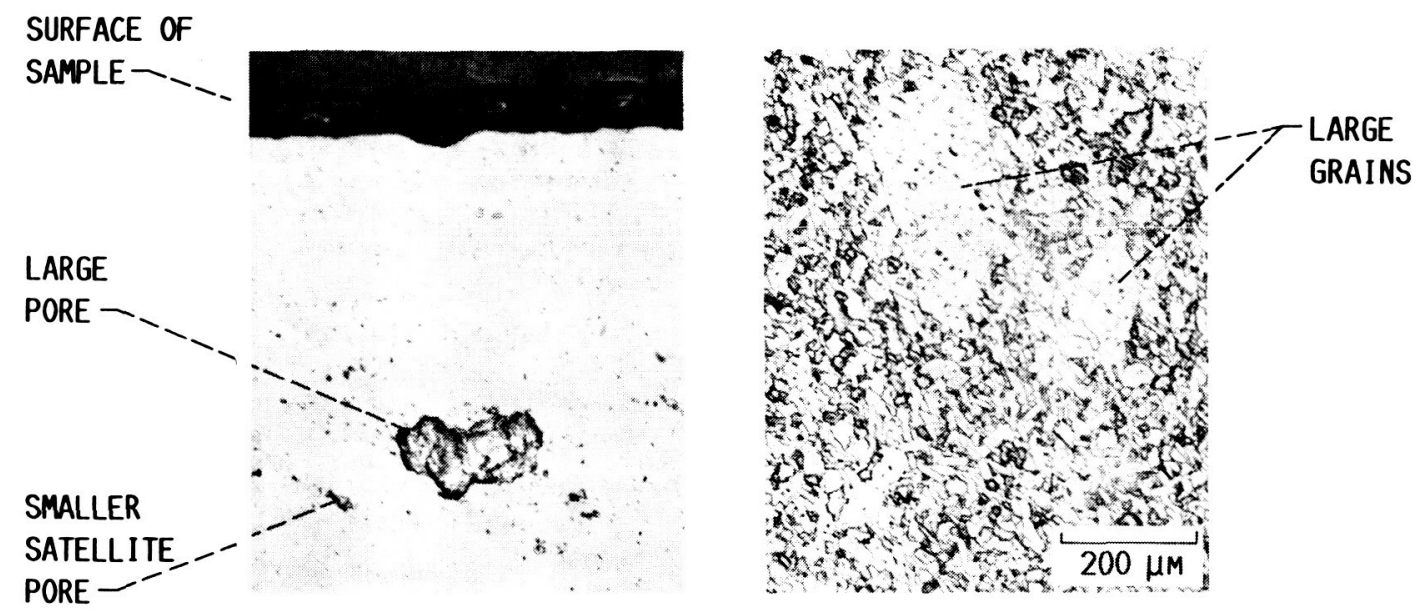

FIGURE 1. - REPRESENTATIVE FLAWS IN MONOL ITHIC SILICON CARBIDE. 


\section{OAEGNAE PAGE IS}

OF POOR QUALITY

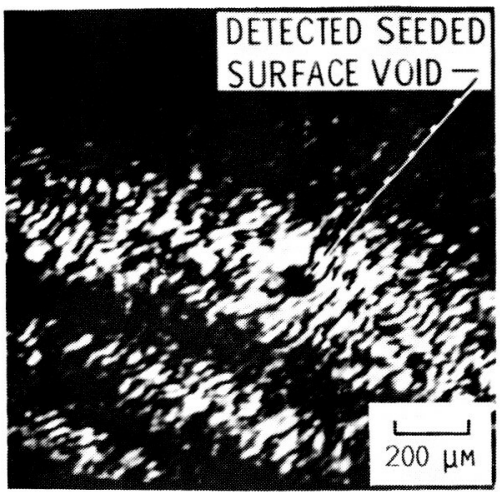

AS-FIRED SURFACE

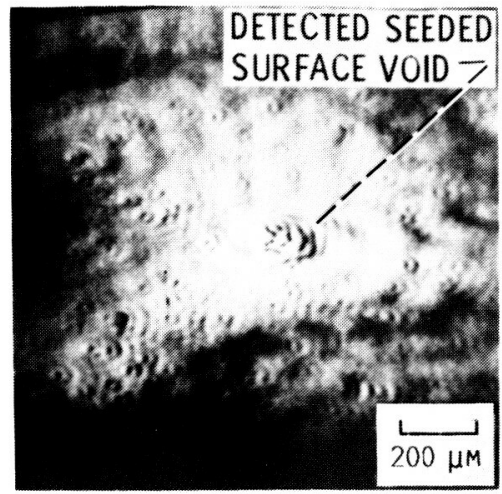

POLISHED SURFACE

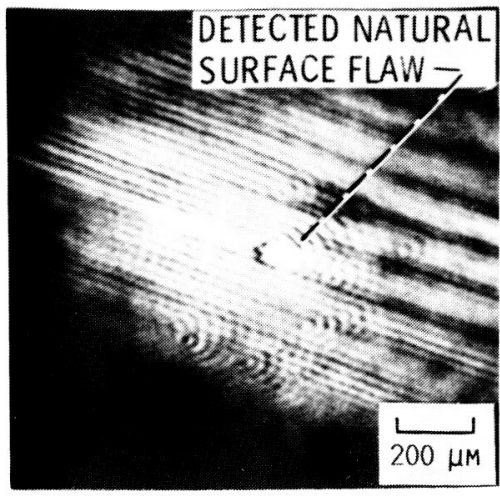

DIAMOND-GROUND SURFACE

FIGURE 2. - SLAM (SCANNING LASER ACOUSTIC MICROSCOPY) IMAGES OF FLAWS IN SINTERED SILICON CARBIDE SPECIMENS.

SPECIMEN THICKNESS $=2 \mathrm{MM}$

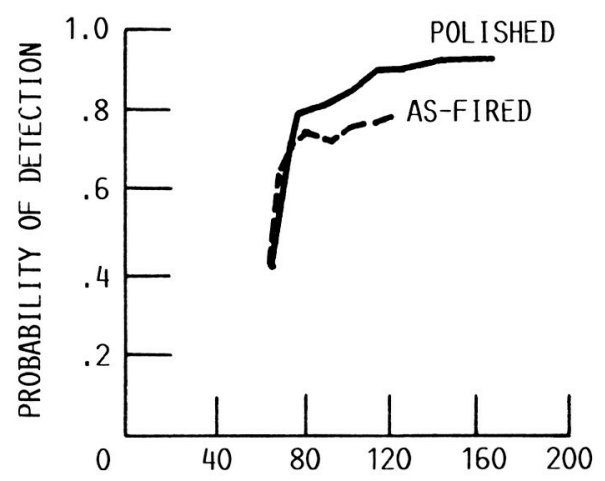

$3 \mathrm{MM}$

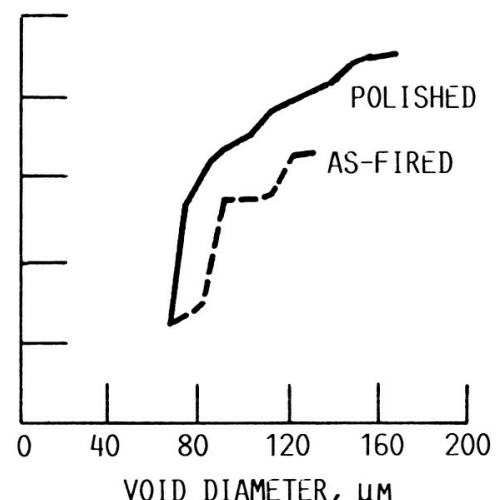

4 MM

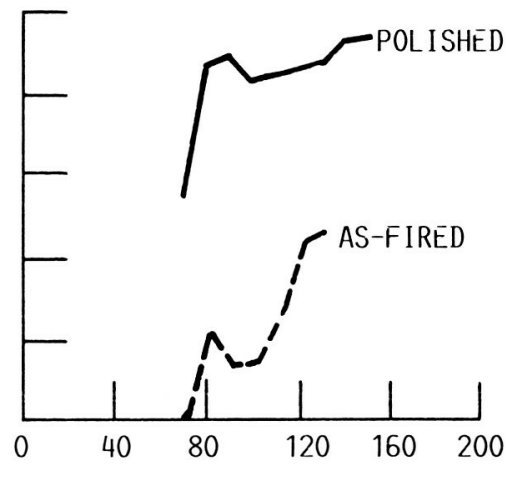

FIGURE 3. - EFFECT OF SURFACE CONDITION AND SPECIMEN THICKNESS ON DETECTABILITY OF VOIDS IN SINTERED SILICON NITRIDE WITH SLAM (SCANNING LASER ACOUSTIC MICROSCOPY). PROBABILITY OF DETECTION CALCULATED AT 0.95 CONFIDENCE LEVEL.

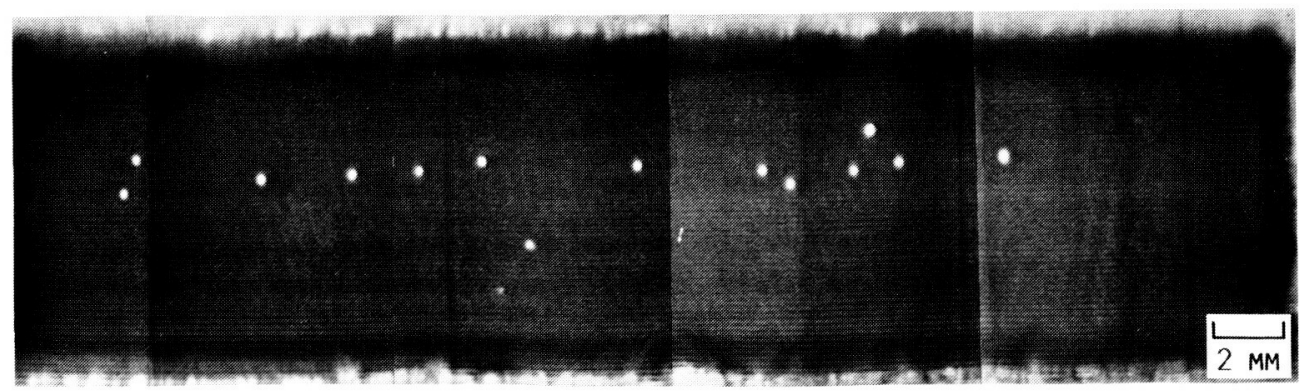

FIGURE 4. - SAM (SCANNING ACOUSTIC MICROSCOPY) IMAGES OF VOIDS IN SINTERED SILICON NITRIDE SPECIMEN. VOID DEPTH $=1 \mathrm{MM}$, DIAM $=20 \mu \mathrm{M}$, SPECIMEN SURFACE DIAMOND GROUND. 

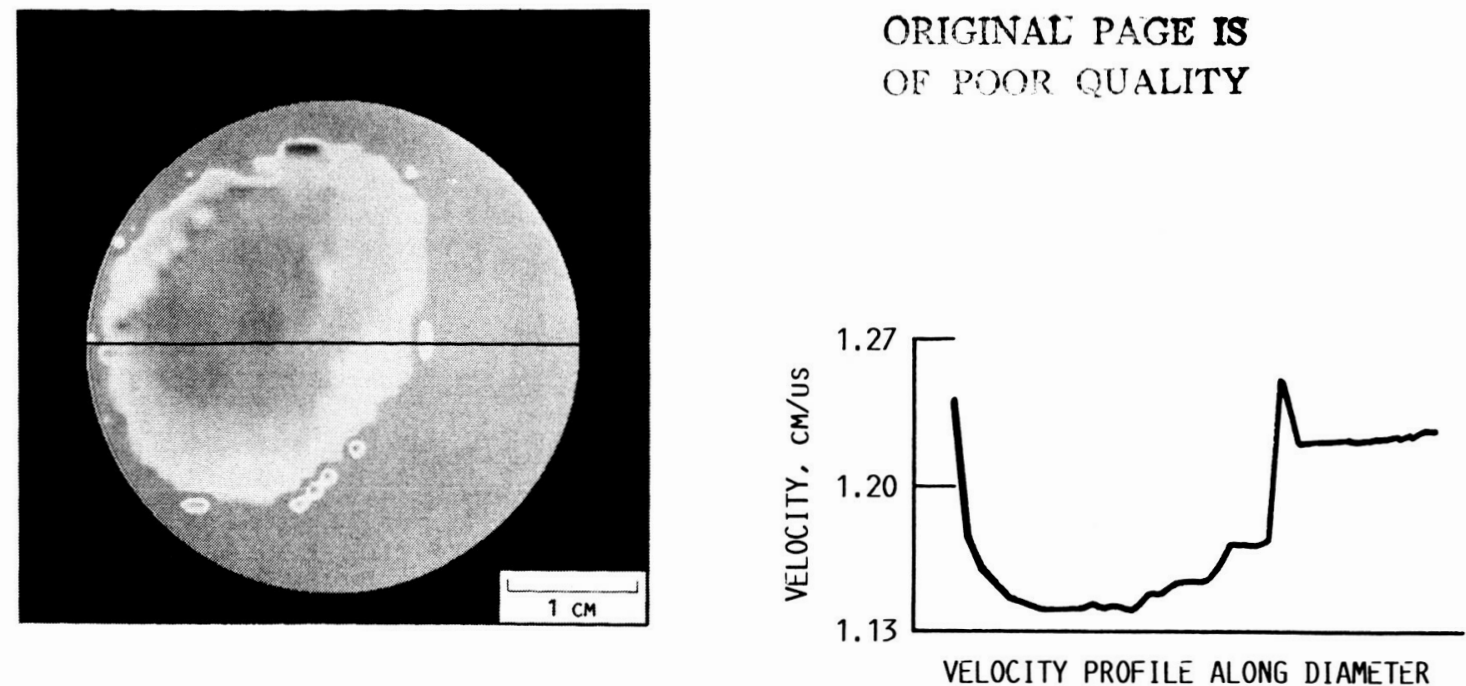

FIGURE 5. - MAPPING OF VELOCITY VARIATIONS IN MONOLITHIC SILICON CARBIDE DISC SINTERED AT $2190{ }^{\circ} \mathrm{C}$. THICKNESS $=5 \mathrm{MM}$, MEAN DENSITY $=3.12 \mathrm{~g} / \mathrm{cm}^{3}$.
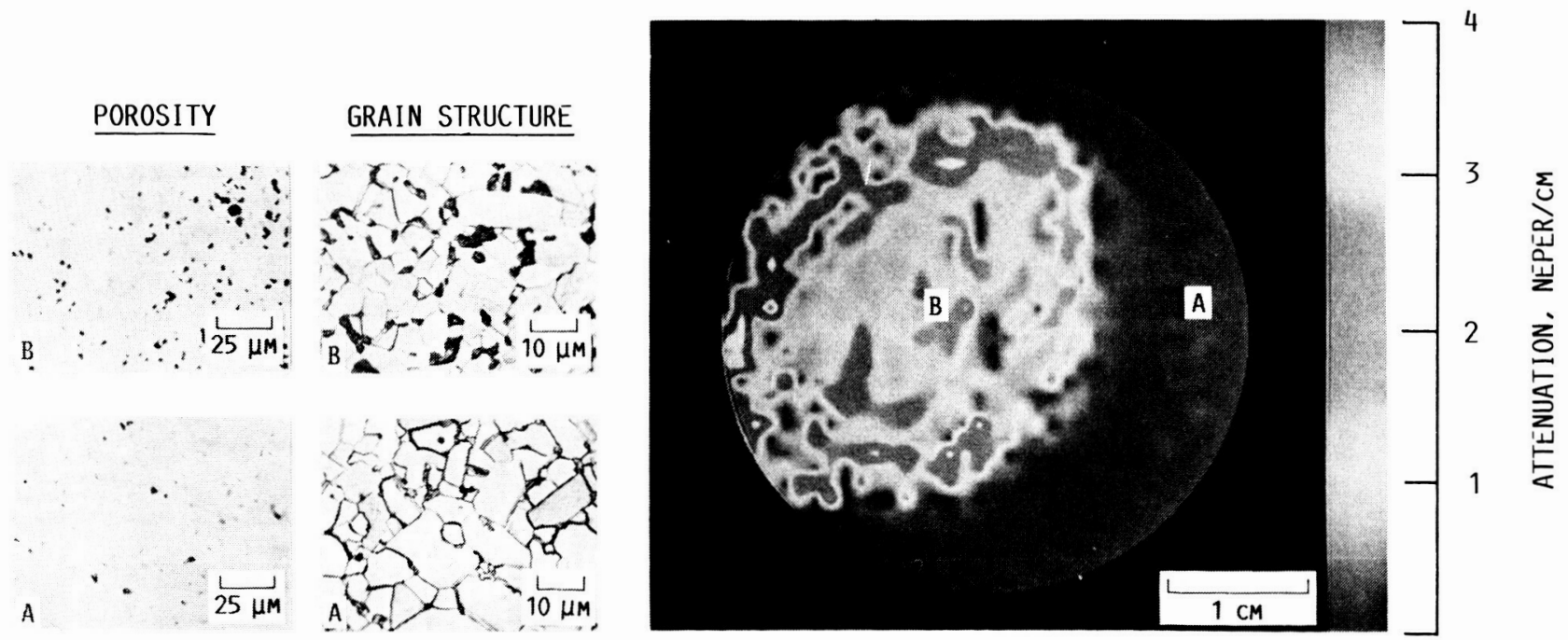

FIGURE 6. - MAPPING OF ATTENUATION VARIATIONS IN MONOLITHIC SILICON CARBIDE DISC OF FIGURE 5. PHOTOMICROGRAPHS SHOW POROSITY (POLISHED, UNETCHED) AND GRAIN STRUCTURE (POLISHED, ETCHED) IN TWO AREAS WITH DIFFERENT ATTENUATION. 


\begin{tabular}{|c|c|c|c|c|c|c|}
\hline \multirow[b]{2}{*}{ SAMPLE } & \multicolumn{3}{|c|}{ SINTERING CONDITIONS } & \multirow{2}{*}{$\begin{array}{c}\text { MEAN } \\
\text { DENSITY, } \\
\mathrm{g} / \mathrm{CM}^{3}\end{array}$} & \multirow{2}{*}{$\begin{array}{c}\text { MEAN } \\
\text { GRAIN, } \\
\mu M\end{array}$} & \multirow{2}{*}{$\begin{array}{c}\text { MEAN } \\
\text { VELOCITY } \\
\text { CM/MS }\end{array}$} \\
\hline & $\begin{array}{l}\text { TEMPERATURE, } \\
{ }^{0} \mathrm{C}\end{array}$ & $\begin{array}{c}\text { TIME， } \\
\text { HR }\end{array}$ & $\begin{array}{c}\text { PRESENT, } \\
\text { ATM }\end{array}$ & & & \\
\hline A & 2300 & 1.0 & 1 & 3.054 & 12 & 1.165 \\
\hline B & 2150 & 4.0 & 1 & 3.058 & 4 & 1.167 \\
\hline$C$ & 2200 & 0.5 & 1 & 3.117 & 6 & 1.180 \\
\hline
\end{tabular}

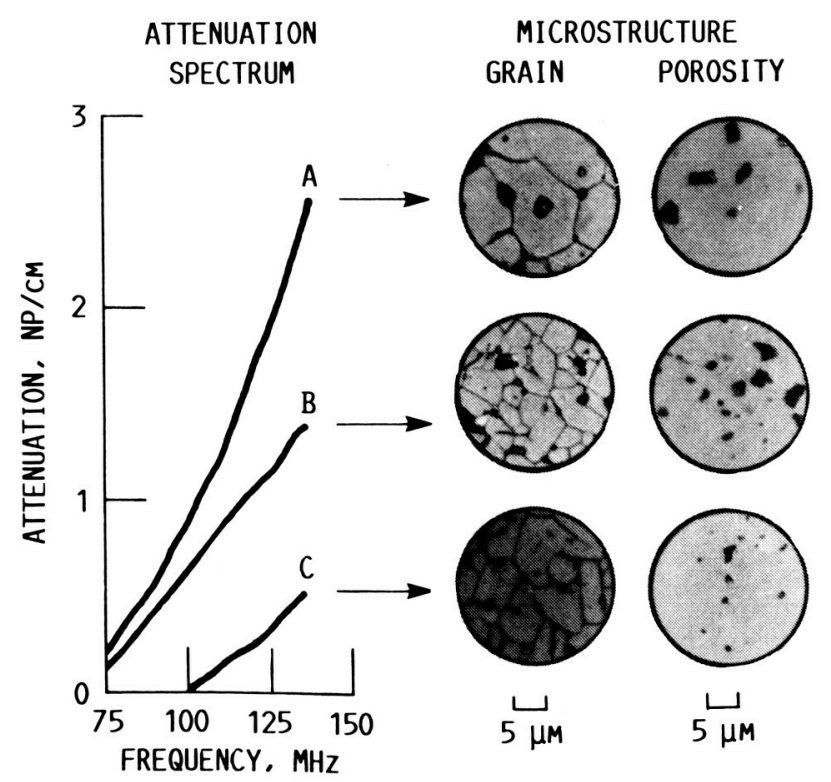

FIGURE 7. - REPRESENTATIVE ATTENUATION SPECTRA FOR THREE SAMPLES OF MONOLITHIC SILICON CARBIDE WITH DELIBERATELY VARIED MICROSTRUCTURES. 


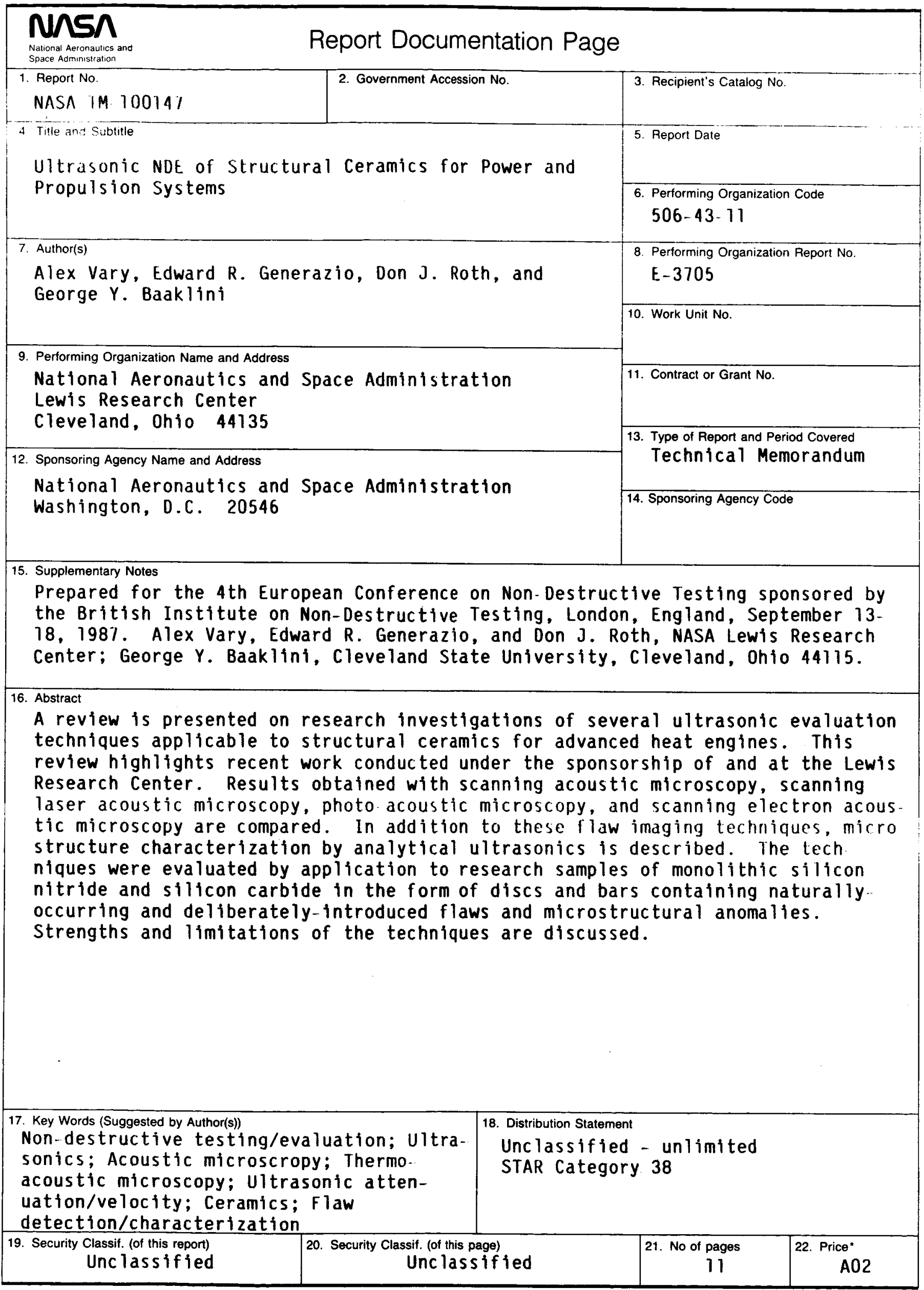

